\title{
Quantificação do Inóculo de Diplodia macrospora e de D. maydis em Restos Culturais, no Ar, e sua Relação com a Infecção em Grãos de Milho*
}

\author{
Erlei M. Reis \& Justino L. Mario \\ Faculdade de Agronomia e Medicina Veterinária, Universidade de Passo Fundo, Cx. Postal, 61, Passo Fundo, RS, \\ CEP 99001-970, e-mail:erleireis@uol.com.br
}

(Aceito para publicação em 28/01/2003)

Autor para correspondência: Erlei Melo Reis

REIS, E.M. \& MÁRIO, J.L. Quantificação do inóculo de Diplodia macrospora e de D. maydis em restos culturais, no ar, e sua relação com a infecção em grãos de milho. Fitopatologia Brasileira:143-147. 2003.

\section{RESUMO}

A quantificação do inóculo de Diplodia macrospora e de $D$. maydis nos restos culturais do milho (Zea mays) é fundamental para demonstrar a importância desta fonte de inóculo, bem como servir de base para o desenvolvimento de estratégias alternativas de controle. Em experimentos conduzidos no campo, nas safras de verão de 1995/96 e 1996/97, quantificaram-se a quantidade de restos culturais do milho sobre o solo após a semeadura, a densidade de conídios nos resíduos e o inóculo disseminado pelo ar, bem como a incidência de cada espécie de Diplodia nos grãos de milho colhidos. A quantidade de conídios nos restos culturais foi de 2,1 x $10^{5}$, para $D$. macrospora, e de $1,0 \times 10^{5}$ para $D$. maydis, no primeiro ano e de $4,2 \times 10^{5}$ e $3,4 \times 10^{6} \mathrm{~m}^{-2}$, respectivamente, no segundo. A dispersão anemófila de conídios foi mais intensa da semeadura até a quarta semana para D. maydis, e da décima semana até a colheita para $D$. macrospora. O número médio de conídios por cirro foi de 865 para $D$. macrospora e de 685 para $D$. maydis. A incidência média nos grãos foi de $75,5 \%$ para D. macrospora e de $25,5 \%$ para $D$. maydis. Com este trabalho, observou-se a importância relativa das espécies de Diplodia envolvidas no processo infeccioso de espigas de milho, demonstrando-se que $D$. macrospora foi a mais freqüente. Comprovou-se também que os restos culturais são necessários à sobrevivência desses patógenos na área cultivada, servindo como fonte de inóculo à infecção da planta e espigas de milho.

Palavras-chave adicionais: fonte de inóculo, podridão de Diplodia, plantio direto.

\begin{abstract}
Quantification of Diplodia macrospora and D. maydis inoculum in crop residues, in the air, and its relationship with infection of corn kernels

The inoculum quantification of Diplodia macrospora and D. maydis is important for a better understanding of the role of plant debris as source of inoculum for corn (Zea mays) ear rots and for developing alternative control strategies for these diseases. Field trials carried out during the summer crops of 1995/96 and 1996/97, quantified the amount of plant debris remaining on the soil surface after harvest, the number of conidia on such debris, and the airborne inoculum of D. macrospora and D. maydis were quantified. The incidence of each fungus species in the harvested

grains was also determined. The conidium number in plant debris was higher in $D$. macrospora $\left(2,1 \times 10^{5} \mathrm{~m}^{-2}\right)$ than in $D$. maydis $\left(1,0 \times 10^{5} \mathrm{~m}^{-2}\right)$ in $1995 / 96$ but lower in $1996 / 97\left(4,2 \times 10^{5}\right.$ vs. 3,4 x $10^{6} \mathrm{~m}^{-2}$ ). While the airborne inoculum of $D$. maydis increased from planting to the fourth week, conidia of D. macrospora were more numerous from the tenth week to harvest. The average incidence of each fungus species in grains was $74 \%$ in $D$. macrospora and $26 \%$ in D. maydis. These results showed the relative importance of each fungus species in the infection of corn ears and grains. The plant debris remaining on the soil surface was shown to be essential to survival and infection of corn plants and ears by these pathogens.
\end{abstract}

\section{INTRODUÇÃO}

Com uma área cultivada de aproximadamente quatro milhões de hectares, o milho (Zea mays L.)é a segunda cultura em importância econômica no Sul do Brasil (Recomendações, 1996). Entre as principais doenças dessa cultura, destacam-se as podridões do colmo e da espiga, causadas, principalmente, por Fusarium moniliforme Sheld (Pereira \& Pereira, 1976;

\footnotetext{
*Parte da dissertação de mestrado do segundo autor. Universidade de Passo Fundo (1998).
}

Shurtleff, 1992), F. graminearum Schw (Rheeder et al., 1990), Diplodia maydis (Berk.) Sacc. (Pereira \& Pereira, 1976; Shurtleff, 1992) e D. macrospora Earle (Mora \& Moreno, 1984; Rheeder et al., 1990). Coincidentemente, os patógenos envolvidos com as podridões da base do colmo são os mesmos que causam podridões da espiga e, conseqüentemente, os que infetam as sementes (Thompson et al., 1971; McGee, 1988; Del Rio \& Zúniga, 1991; Casa, 1997). Entre esses patógenos, destacam-se os fungos do gênero Diplodia. Recentemente, Mario \& Prestes (1997) relataram a ocorrência de D. macrospora em milho, causando manchas foliares, no 


\section{Rio Grande do Sul.}

As principais fontes de inóculo de D. macrospora e D. maydis são sementes infetadas (McGee, 1988; Casa, 1997) e os restos culturais (Marasas \& Van Der Westhuizen, 1979; Casa, 1997). Os resíduos culturais, mantendo os parasitas na fase saprofítica e permanecendo na superfície do solo de uma estação de cultivo para a outra, servem como fonte de inóculo para as podridões do colmo e da espiga (Ullstrup, 1964; Scott et al., 1994). Por isso, a quantificação do inóculo de D. maydis e D. macrospora permite determinar a importância dos restos culturais como fonte de inóculo e o desenvolvimento de estratégias de controle. Também é importante determinar quais são as espécies de Diplodia envolvidas na patogênese e suas freqüências.

A partir dos restos culturais infetados, os esporos são liberados dos picnídios e levados pelo vento aos sítios de infecção. Uma vez o inóculo tendo sido depositado nas espigas, infetam e colonizam os seus tecidos (Shurtleff, 1992).

Formulou-se a hipótese de que a presença dos restos culturais numa lavoura indica a presença dos patógenos na área de cultivo. Este trabalho teve por objetivo quantificar a densidade de inóculo de $D$. macrospora e $D$. maydis nos restos culturais do milho, a disseminação de conídios pelo ar e a incidência dos patógenos nos grãos colhidos.

\section{MATERIAL E MÉTODOS}

As ações de pesquisa foram conduzidas no Centro de Pesquisa da Braskalb Agropecuária Brasileira Ltda., localizado em Coxilha, RS, e no Laboratório de Fitopatologia da Faculdade de Agronomia e Medicina Veterinária da Universidade de Passo Fundo, RS, nas safras 1995/96 e 96/ 97. A área experimental foi cultivada com seis híbridos (AG 9012, C 808, C 901, P 3041, X 9403, e XL 212) previamente selecionados para esse estudo. A semeadura foi feita no sistema plantio direto, em área com dois monocultivos de milho e, portanto, com a totalidade dos restos culturais permanecendo na superfície do solo.

\section{Quantificação dos restos culturais do milho sobre o solo}

$\mathrm{Na}$ área experimental, determinou-se a quantidade de restos culturais de milho existentes na superfície do solo após a semeadura. Foram tomadas ao acaso dez amostras de palha, cada uma com área de $0,25 \mathrm{~m}^{2}$. No laboratório, as amostras foram secas ao ar e pesadas para determinação da massa seca $\mathrm{m}^{-2}$. Na mesma amostra, determinaram-se, ainda, as densidades de inóculo de $D$. maydis e de $D$. macrospora presentes nos restos culturais.

\section{Estimativa da densidade de inóculo em restos culturais}

De cada sub-amostra coletada no campo, obteve-se uma sub-amostra de trabalho com $10 \mathrm{~g}$ de resto cultural, que foi introduzida em um Becker de $500 \mathrm{ml}$ de volume, ao qual se adicionaram $300 \mathrm{ml}$ de água. A suspensão foi agitada por 5 min para remoção das partículas de solo. Após, verteu-se a água, e a palha removida foi seca ao ar por $24 \mathrm{~h}$. Findo esse período, a palha foi novamente introduzida em frascos Erlenmeyers, acrescida de $300 \mathrm{ml}$ de água mais uma gota de espalhante (Triton X-100) (proporção de $1 \mathrm{ml} \mathrm{l}^{-1}$ de água). Os frascos foram colocados em uma mesa agitadora a 168 rotações $\min ^{-1}$, por $5 \mathrm{~min}$, para liberação e remoção dos conídios. A suspensão foi filtrada através de duas camadas de gaze para o interior de Erlenmeyers de $250 \mathrm{ml}$ de volume. A seguir, mediu-se o volume médio de uma gota dessa suspensão com uma pipeta de $1 \mathrm{ml}$ (1/100). Conhecido o volume médio, depositou-se uma gota sobre uma lâmina de microscópio e procedeu-se à identificação e contagem dos esporos por varredura de toda a superfície de uma lamínula com 7,68 $\mathrm{cm}^{2}$, com microscópio utilizando-se a objetiva com magnitude de 10x. Esse procedimento foi repetido quatro vezes para cada amostra de trabalho. Finalmente, calculou-se o número médio de conídios por grama de resto cultural. Os resultados foram expressos por número de esporos $\mathrm{m}^{-2}$ de solo para ambas as espécies alvo deste estudo.

\section{Disseminação do inóculo de Diplodia spp.}

Para quantificar a dispersão anemófila dos conídios dos fungos alvo, a partir dos restos culturais infetados saprofiticamente, foram instalados quatro coletores de esporos tipo cata-vento (Reis \& Santos, 1985) a 0,5 m da superfície do solo na área central do experimento. Cada coletor continha uma lâmina de microscopia untada com vaselina medicinal. As avaliações foram semanais e feitas através da leitura das lâminas. Quando as plantas de todas as cultivares atingiram $100 \%$ da floração feminina, os coletores foram posicionados na altura das espigas. Em laboratório, procedeu-se à identificação e à quantificação dos esporos presentes nas lâminas, com microscópio, a uma magnitude de 10x. Para esse procedimento, verteram-se cinco gotas de lactofenol sobre a lâmina, cobrindo-a com uma lamínula de $7,68 \mathrm{~cm}^{2}$. Os resultados foram expressos em número de conídios $/ 7,68 \mathrm{~cm}^{2}$ correspondentes à área de leitura da lamínula.

\section{Incidência de Diplodia spp. em grãos de milho}

Após a colheita, semearam-se 100 grãos de cada cultivar em caixas plásticas tipo gerbox, com três camadas de papel-de-filtro umedecidos com água-esterilizada. $\mathrm{O}$ material foi incubado em câmara de crescimento com fotoperíodo de $12 \times 12 \mathrm{~h}$ e temperatura de $25 \pm 2{ }^{\circ} \mathrm{C}$. Decorridos 15 dias, identificaram-se as colônias das duas espécies desenvolvidas sobre o papel-de-filtro com base na metodologia desenvolvida por Mario \& Reis (2001).

\section{RESULTADOS E DISCUSSÃO}

\section{Quantificação de restos culturais do milho sobre o solo}

Os restos culturais podem servir como abrigo e fonte nutricional para fitopatógenos que apresentam em seu ciclo de vida a fase saprofítica (Scott et al., 1994; Reis \& Casa, 1998). Daí decorre a importância de se quantificar os resíduos existentes na lavoura, o período de decomposição até a exaustão nutricional e o inóculo de fitopatógenos neles 
disponível. A massa de restos culturais do milho remanescente sobre o solo em plantio direto foi de 287 g.m $\mathrm{m}^{-2}$ e 348 g.m ${ }^{-2}$ no primeiro e no segundo ano, respectivamente. Em cereais de inverno, foi demonstrado que a quantidade de inóculo de fungos fitopatogênicos disponível numa lavoura é proporcional à quantidade de restos culturais infetados que permanecem na superfície do solo (Reis et al., 1992). Em milho, tem sido relatado que a principal fonte de inóculo de Diplodia spp. são os restos culturais infetados. Porém, não se encontrou na literatura consultada trabalho no qual tenha sido avaliada a quantidade de restos culturais remanescentes sobre o solo no sistema plantio direito e sua relação com o inóculo disponível. Estratégias visando ao controle das podridões brancas da espiga podem basear-se na eliminação dos restos culturais através da rotação de culturas (Scott et al., 1994). Desse fato decorre a importância das informações geradas nesta investigação.

\section{Densidade de inóculo nos restos culturais do milho}

De acordo com os resultados das avaliações (Tabela 1), observou-se que a densidade de conídios de D. macrospora e D. maydis nos restos culturais foi maior na safra 1996/97 do que na safra 1995/96 (Tabela 1). Na primeira safra, o fungo que apresentou maior densidade de inóculo foi $D$. macrospora. É importante chamar a atenção para esse fato, pois, embora a maioria dos trabalhos publicados no Brasil se refira a $D$. maydis como um dos patógenos mais freqüentes em milho, na presente investigação, obteve-se uma frequiência similar para as duas espécies.

Algumas inferências podem ser feitas em relação a trabalhos publicados, como, por exemplo, da possibilidade de se ter confundido os dois patógenos, em meio de cultura, quando da diagnose com base na coloração do micélio. Porém, hoje, com o método descrito por Mario \& Reis (2001), pode-se proceder com maior segurança à identificação das duas espécies de Diplodia sobre papel-defiltro. Por outro lado, não se encontrou referência na literatura sobre a quantificação da densidade de inóculo desses patógenos nos restos culturais do milho. A respeito, encontraram-se informações pouco precisas, as quais se referem apenas aos restos culturais como fonte de inóculo para ambos os fungos (Marasas \& Van Der Westhuizen, 1979; Scott et al., 1994), sem nenhuma informação quantitativa. Demonstra-se aqui que a presença dos restos culturais do milho pode indicar também a presença do inóculo desses parasitas na área cultivada. Apresenta-se a necessidade de sua redução da área cultivada mediante a rotação de culturas com espécies vegetais não hospedeiras comuns dos parasitas, como por exemplo soja [Glycine max (L.) Merril] $\mathrm{x}$ milho, no verão.

Deve-se ressaltar que, na África do Sul, um dos principais fungos associados à podridão da espiga do milho é D. macrospora (Marasas \& Van Der Westhuizen, 1979). Há, pois, uma semelhança dos dados aqui obtidos com os relatos sul-africanos sobre a importância de D. macrospora em relação a $D$. maydis.
TABELA 1 - Densidade de conídios de Diplodia spp. em restos culturais de milho (Zea mays) na área experimental, nas safras de 1995/96 e 1996/97, em Coxilha, RS

\begin{tabular}{|c|c|c|c|c|}
\hline \multirow{3}{*}{ Amostra } & \multicolumn{4}{|c|}{ Conídios $\mathrm{m}^{-2}$ de superfície de solo } \\
\hline & \multicolumn{2}{|c|}{ Diplodia maydis } & \multicolumn{2}{|c|}{ Diplodia macrospora } \\
\hline & $1995 / 96$ & $1996 / 97$ & $1995 / 96$ & $1996 / 97$ \\
\hline 1 & $1,8 \times 10^{5 z}$ & $6,2 \times 10^{5}$ & $3,0 \times 10^{5}$ & $7,3 \times 10^{5}$ \\
\hline 2 & $4,3 \times 10^{5}$ & $1,2 \times 10^{4}$ & $2,3 \times 10^{5}$ & $1,6 \times 10^{6}$ \\
\hline 3 & $4,5 \times 10^{4}$ & $2,9 \times 10^{3}$ & $1,3 \times 10^{4}$ & $4,9 \times 10^{3}$ \\
\hline 4 & $4,2 \times 10^{4}$ & $1,4 \times 10^{6}$ & $4,0 \times 10^{4}$ & $5,2 \times 10^{5}$ \\
\hline 5 & $5,3 \times 10^{4}$ & $3,4 \times 10^{5}$ & $1,4 \times 10^{5}$ & $2,4 \times 10^{5}$ \\
\hline 6 & $3,9 \times 10^{4}$ & $9,8 \times 10^{6}$ & $3,3 \times 10^{4}$ & $3,5 \times 10^{4}$ \\
\hline 7 & $1,8 \times 10^{4}$ & $1,7 \times 10^{7}$ & $3,2 \times 10^{5}$ & $3,7 \times 10^{5}$ \\
\hline 8 & $5,1 \times 10^{4}$ & $1,1 \times 10^{7}$ & $1,1 \times 10^{5}$ & $6,1 \times 10^{5}$ \\
\hline 9 & $1,1 \times 10^{5}$ & $6,2 \times 10^{5}$ & $4,1 \times 10^{5}$ & $2,4 \times 10^{4}$ \\
\hline 10 & $2,2 \times 10^{4}$ & $2,6 \times 10^{6}$ & $4,9 \times 10^{5}$ & $5,1 \times 10^{5}$ \\
\hline Média (ano) & $1,0 \times 10^{5}$ & $3,4 \times 10^{6}$ & $2,1 \times 10^{5}$ & $4,2 \times 10^{5}$ \\
\hline Média (fungo) & \multicolumn{2}{|c|}{$1,7 \times 10^{6}$} & \multicolumn{2}{|c|}{$3,1 \times 10^{5}$} \\
\hline
\end{tabular}

Tanto no primeiro quanto no segundo período de safra a maior densidade foi de $D$. macrospora (Tabela 1 ). Por outro lado, quanto a infecção natural dos grãos, houve a predominância de D. macrospora (Tabela 2).

\section{Disseminação anemófila de Diplodia spp.}

Os esporos de Diplodia spp. são disseminados principalmente pelo vento (Del Rio \& Melara, 1991). Neste trabalho, observou-se que a dispersão dos esporos de D. maydis foi mais intensa nas primeiras três semanas após o plantio (Figura 1). Nessa época, as plantas apresentavam pouco desenvolvimento vegetativo, e os coletores de esporos estavam posicionados a $0,50 \mathrm{~m}$ da superfície do solo. Nesse caso, o ar em movimento atingia diretamente os coletores. Por outro lado, a partir da décima semana de avaliação, a dispersão dos conídios de D. macrospora apresentou valores maiores do que de D. maydis; onde, os coletores estavam posicionados à altura das espigas. Outro fato importante constatado neste trabalho, foi que o vento não dissemina somente os conídios isoladamente desses fungos, mas pode transportar também os cirros de ambas as espécies. O maior número de cirros de D. maydis foi coletado nas primeiras semanas após o plantio, quando as plantas de milho estavam baixas e os coletores, a $0,5 \mathrm{~m}$ da superfície do solo. O contrário ocorreu em relação a D. macrospora, para a qual a maioria dos cirros foi coletada a partir da décima semana, quando havia uma grande massa foliar e os coletores estavam posicionados à altura das espigas. $\mathrm{O}$ cirro de $D$. macrospora com a maior quantidade de esporos continha 865 conídios, enquanto o de D. maydis apresentou 685 conídios (Tabela 3 ).

Esse aumento na quantidade de esporos de $D$. macrospora pode, provavelmente, ser atribuído à esporulação de D. macrospora em lesões foliares, e portanto próximas aos coletores.

Esses números comprovam a importância do vento na disseminação tanto de conídios como de cirros. Não foram 
TABELA 2 - Incidência de Diplodia maydis e D. macrospora em grãos de milho (Zea mays) naturalmente infetados, nas safras 1995/ 96 e 1996/97, em Coxilha, RS

\begin{tabular}{|c|c|c|c|c|}
\hline \multirow[b]{2}{*}{ Híbrido } & \multicolumn{2}{|c|}{$1995 / 96$} & \multicolumn{2}{|c|}{$1996 / 97$} \\
\hline & $\underset{\text { maydis }}{\text { D. }}$ & $\begin{array}{c}D . \\
\text { macrospora }^{(1)}\end{array}$ & $\underset{\text { maydis }}{D}$ & $\begin{array}{c}\text { D. } \\
\text { macrospora } \\
(1)\end{array}$ \\
\hline AG 9012 & 15 & 85 & 37 & 63 \\
\hline C 808 & 25 & 75 & 29 & 71 \\
\hline C 901 & 28 & 72 & 47 & 53 \\
\hline P 3041 & 11 & 89 & 29 & 71 \\
\hline XL 212 & 15 & 85 & 37 & 63 \\
\hline X 9403 & 5 & 95 & 28 & 72 \\
\hline Média & 16,5 & 83,5 & 34,5 & 65,5 \\
\hline
\end{tabular}

(1)Percentual de D. maydis e D. macrospora em relação ao percentual de Diplodia spp. da amostra.

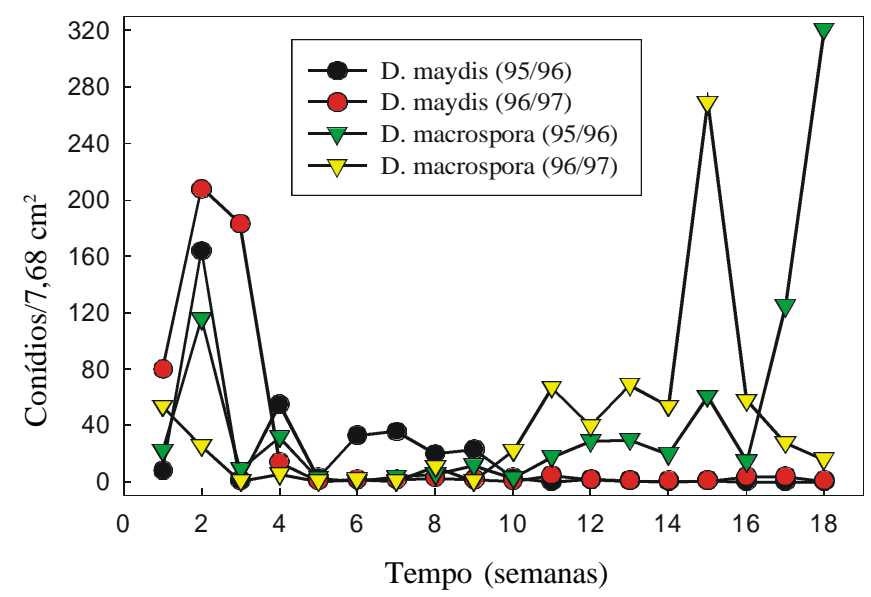

FIG. 1 - Dispersão anemófila de Diplodia spp.

encontrados na literatura consultada trabalhos que relatem a quantificação de cirros e de conídios no ar e, principalmente, o transporte de cirros pelo vento.

\section{Incidência de Diplodia spp. em grãos de milho}

A liberação dos esporos de D. macrospora deve ter ocorrido a partir dos picnídios formados nas manchas foliares próximas das espigas. Esse fato pode explicar também a maior incidência de D. macrospora em grãos de milho nos dois anos do experimento havendo, por conseguinte, uma influência na densidade do inóculo no ar (Figura 1) e nos grãos (Tabela 3). Tais fatos, estão de acordo com os relatos feitos por Koehler (1959) e Ullstrup (1970). Na média, a incidência de D. macrospora nos grãos, nos dois anos, foi de $75,5 \%$, contra $25,5 \%$ de D. maydis.

A distinção entre as duas espécies de Diplodia mostra a importância que $D$. macrospora tem na infecção de grãos e de restos culturais do milho no Planalto Médio do Rio Grande do Sul. Trabalhos posteriores a este devem levar em conta as duas espécies distintamente e não mais de forma conjunta. $\mathrm{O}$ fungo $D$. macrospora não está recebendo a devida atenção por ser confundido com outros patógenos nas podridões do colmo, espiga e nas manchas foliares, especialmente a helmintosporiose causada por Exserohilum turcicum (Mario \& Prestes, 1997).

TABELA 3 - Número de conídios por cirro de Diplodia maydis e D. macrospora quantificados semanalmente durante o ciclo da cultura de milho (Zea mays), nas safras de 1995/96 e 1996/97, em Coxilha, RS

\begin{tabular}{cccccc}
\hline \hline \multirow{2}{*}{ Semana } & \multicolumn{2}{c}{$\mathbf{1 9 9 5 / 1 9 9 6}$} & \multicolumn{2}{c}{$\mathbf{1 9 9 6 / 1 9 9 7}$} \\
\cline { 2 - 5 } \cline { 3 - 5 } & D. maydis & $\begin{array}{c}\boldsymbol{D} \text {. } \\
\text { macrospora }\end{array}$ & D. maydis & $\begin{array}{c}\text { D. } \\
\text { macrospora }\end{array}$ \\
\hline 1 & - & - & 121 & 167 \\
3 & $184-425^{z}$ & 201 & $227-487$ & 63 \\
4 & - & - & $202-275$ & - \\
5 & 316 & 119 & 256 & - \\
6 & - & - & - & - \\
7 & 100 & - & - & - \\
8 & 214 & - & 141 & - \\
9 & 103 & - & - & - \\
10 & 126 & 166 & - & - \\
11 & - & - & - & 54 \\
12 & - & 96 & - & 158 \\
13 & - & - & - & - \\
14 & - & $100-198$ & - & 177 \\
15 & - & $122-168$ & - & $107-115$ \\
16 & - & 347 & - & 865 \\
17 & - & - & 86 & 163 \\
18 & 685 & $267-356$ & 56 & $59-107$ \\
\hline Média & - & 805 & - & - \\
\hline
\end{tabular}

z- Refere-se ao número de conídios de dois cirros presentes por lâmina.

\section{REFERÊNCIAS BIBLIOGRÁFICAS}

CASA, R.T. Diplodia maydis e D. macrospora associadas à semente de milho (Dissertação de Mestrado).Viçosa. Universidade Federal de Viçosa. 1997.

DEL RIO, L. \& MELARA, W. Dispersion de Stenocarpella maydis (Berk.) Sutton en un cultivo de maiz. Ceiba 32:133-140. 1991.

DEL RIO, L. \& ZÚNIGA, T. Efecto de algunas practicas culturales y fechas de recoleccion en la incidencia de Stenocarpella maydis (Berk.) Sutton en maiz sembrado en dos sistemas de labranza. Ceiba 32:141-149. 1991.

KOEHLER, B. Corn ear rots in Illinois. University Of Illinois. Agriculture Experimental Station Bolletin 639. 1959.

MARASAS, W.F.O. \& VAN DER WESTHUIZEN, G.C.A. Diplodia macrospora:the cause of a leaf blight and cob rot of maize (Zea mays) in South Africa. Phytophylactica 11:61-64. 1979.

MARIO, J.L. \& PRESTES, A.M. Avaliação da resistência à mancha foliar causada por Diplodia macrospora em genótipos de milho. Fitopatologia Brasileira 22:280. 1997. (Suplemento).

MARIO, J.L. \& REIS, E.M. Método simples para diferenciar Diplodia maydis de D. macrospora em testes de patologia de sementes de milho. Fitopatologia Brasileira 26:670-672. 2001.

McGEE, D.C. Maize diseases: a reference source for seed technologists. American Phytophathological Society. St ${ }^{\mathrm{a}}$. Paul, Minnesota. 1988. 
MORA, L.E. \& MORENO, R.A. Cropping pattern and soil management influence on plant diseases:I. Diplodia macrospora leaf spot of maize. Turrialba 34:35-40. 1984.

PEREIRA, O.A.P. \& PEREIRA, W.S.P. Estudo de Diplodia zeae (Shw.) Lev. e Fusarium moniliforme (Sheldon) em colmos de milho. Summa Phytopathologica 2:157-165. 1976.

RECOMENDAÇÕES técnicas para a cultura do milho no estado do Rio Grande do Sul. Fundação Estadual de Pesquisa Agropecuária; Associação de Empreendimentos de Assistência Técnica e Extensão Rural; Federação das Cooperativas de Trigo e Soja do RS Ltda. Porto Alegre. FEPAGRO. Boletim Técnico, 3. 1996.

REIS, E.M. \& CASA, R.T. Patologia de sementes de cereais de inverno. Passo Fundo. Aldeia Norte Editora. 1998.

REIS, E.M. \& SANTOS, H.P. População de Helminthosporium sativum no ar quantificados através de uma armadilha tipo catavento. Fitopatologia Brasileira 10:515-519. 1985.

REIS, E.M., SANTOS, H.P., LHAMBY, J.C.B. \& BLUM, M.M.C. Effect of soil managment and crop rotation on the control of leaf blotches of wheat in Sauthern Brazil. Anais, I Congresso
Interamericano de Siembra Directa, 1992. Villa Giardino. Trabajos presentados. S.I.: Associacion Argentina Productor em Siembra Directa/Sociedade de Cooperacion de Suelos/Clube Amigos da Terra/Fudação ABC/Associacion Uruguaya Pro Siembra Directa. 1992. pp.217-236.

RHEEDER, J.P., MARASAS, W.O. \& VAN WYK, P.S. Fungal associations corn kernels and effects on germination. Phytopathology 80:131-134. 1990.

SCOTT, D.B., PLESSIS, J.G. \& RENSBURG, J.B.L. et al. Effect of stuble management on cereal diseases caused by soil-borne fungi. Tenth South African Maize Breeding Symposium 238:82-85. 1994.

SHURTLEFF, M.C. A compendium of corn diseases. St ${ }^{\mathrm{a}}$. Paul, Minnesota. American Phytopathological Society. 1992.

THOMPSON, D.L., VILLENA, W.L. \& MAXWELL, J.D. Correlation between Diplodia stalk and ear rot of corn. Plant Disease Reporter 55:158-162. 1971.

ULLSTRUP, A.J. Observations on two epiphytotics of Diplodia ear rot of corn in Indiana. Plant Disease 48:414-415. 1964.

ULLSTRUP, A.J. Methods for inoculating corn ears with Gibberella zeae and Diplodia maydis. Plant Disease 54:658-662. 1970. 